\title{
Comparative genomics of Pseudomonas fluorescens subclade III strains from human lungs
}

Brittan S. Scales ${ }^{1,2}$, John R. Erb-Downward ${ }^{1}$, Ian M. Huffnagle ${ }^{1}$, John J. LiPuma ${ }^{3}$ and Gary B. Huffnagle ${ }^{1,2^{*}}$

\begin{abstract}
Background: While the taxonomy and genomics of environmental strains from the $P$. fluorescens species-complex has been reported, little is known about $P$. fluorescens strains from clinical samples. In this report, we provide the first genomic analysis of $P$. fluorescens strains in which human vs. environmental isolates are compared.

Results: Seven $P$. fluorescens strains were isolated from respiratory samples from cystic fibrosis (CF) patients. The clinical strains could grow at a higher temperature $\left(>34^{\circ} \mathrm{C}\right)$ than has been reported for environmental strains. Draft genomes were generated for all of the clinical strains, and multi-locus sequence analysis placed them within subclade III of the $P$. fluorescens species-complex. All strains encoded type- II, $-I I I,-I V$, and -VI secretion systems, as well as the widespread colonization island (WCl). This is the first description of a WCI in $P$. fluorescens strains. All strains also encoded a complete I2/PfiT locus and showed evidence of horizontal gene transfer. The clinical strains were found to differ from the environmental strains in the number of genes involved in metal resistance, which may be a possible adaptation to chronic antibiotic exposure in the CF lung.

Conclusions: This is the largest comparative genomics analysis of $P$. fluorescens subclade III strains to date and includes the first clinical isolates. At a global level, the clinical P. fluorescens subclade III strains were largely indistinguishable from environmental $P$. fluorescens subclade III strains, supporting the idea that identifying strains as 'environmental' vs 'clinical' is not a phenotypic trait. Rather, strains within P. fluorescens subclade III will colonize and persist in any niche that provides the requirements necessary for growth.
\end{abstract}

Keywords: Pseudomonas fluorescens, Genomics, Human, Lung, Metal, Efflux pumps, Cystic fibrosis

\section{Background}

Members of the $P$. fluorescens species-complex have versatile metabolic capabilities, allowing them to thrive in a large range of environments [1-4]. Strains of P. fluorescens produce a wide-range of secondary metabolites that are important for their association with plants, such as phenazine, polyketides, cyclic lipopeptides, biosurfactants, phytohormones and metabolites that alter plant hormone levels. However, many traits of $P$. fluorescens also benefit its survival in a mammalian host, such as the production of siderophores and bioactive metabolites

\footnotetext{
* Correspondence: ghuff@umich.edu

'Division of Pulmonary and Critical Care Medicine, Department of Internal

Medicine, University of Michigan Medical School, Ann Arbor, MI, USA

${ }^{2}$ Department of Microbiology and Immunology, University of Michigan

Medical School, Ann Arbor, MI, USA

Full list of author information is available at the end of the article
}

and the ability to form biofilms. While environmental strains of $P$. fluorescens have optimal growth temperatures between $4{ }^{\circ} \mathrm{C}$ and $28{ }^{\circ} \mathrm{C}$, there are documented cases of $P$. fluorescens strains with an expanded growth temperature range that allow them to colonize humans [5-8] or interact with human cells in vitro [9-11].

An increasing amount of evidence suggests that some strains of $P$. fluorescens are members of the human microbiota and interact with the human host in ways that contribute to certain chronic diseases (reviewed in [1]). For example, there is a strong link between the presence of circulating antibodies to the P. fluorescensspecific peptide I2 and such autoimmune diseases as Crohn's disease, celiac disease, chronic granulomatous disease and ankylosing spondylitis. We have previously reported that in the absence of acute disease, $P$. fluorescens is cultured from clinical respiratory specimens at a 
low rate in a hospital setting and is common in asymptomatic lung transplant recipients [12]. P. fluorescens strains are often isolated from respiratory specimens from individuals with cystic fibrosis (CF), though this is often unreported (unpublished observation). Additional culture-independent analyses have identified P. fluorescens as a low-abundance member of the human microbiome.

There is a large degree of genetic diversity among bacterial strains classified as $P$. fluorescens, which likely reflects the wide range of growth capabilities in these bacteria. Using multi-locus sequence analysis (MLSA) and 16S rRNA gene classification approaches, the $P$. fluorescens-species complex can be divided into three smaller taxonomic subclades [1-4, 13, 14]. Loper et al., used ten housekeeping genes (acs $A$, aroE, dnaE, guaA, gyrB, mutL, pps $A, p y r C$, recA, and $r p o B$ ) to divide seven fully sequenced strains within the $P$. fluorescens-species complex into these three distinct subclades [3]. Subclade I includes $P$. chlororaphis 30-84, $P$. chlororaphis $\mathrm{O} 6$ and $P$. protegens $\mathrm{Pf}-5$; subclade II includes $P$. fluorescens $\mathrm{Pf0}-$ 1, P. fluorescens Q2-87 and P. brassicacearum Q8r1-96; subclade III includes $P$. fluorescens A506, P. fluorescens SBW25, and Pseudomonas sp. (now known to be P. synxantha) BG33R. As expected, strains within a subclade share a higher proportion of conserved domains than the species-complex as a whole. While the core genome of the P. fluorescens species-complex was found to be comprised of 2,789 genes, the core genomes of subclades I, II and III were found to be comprised of 4,188, 3,729 and 3,893 genes, respectively [3]. Comparative genomic analysis revealed that these subclade divisions correlate with potentially important functional differences. For example, the genes necessary to produce a type-III secretion system (T3SS) were found in subclades II and III, but not subclade I [3].

Much work has been done on the taxonomy and genomics of the $P$. fluorescens species-complex, but as of yet, no strain isolated from a mammalian source has been sequenced. Here we present the first comparative genomic analysis of $P$. fluorescens strains isolated from humans. The seven $P$. fluorescens clinical strains were isolated from respiratory specimens from individuals with cystic fibrosis (CF), and represent the first publically available draft genomes of humanassociated P. fluorescens strains. Phylogenetic analysis reveals that these seven clinical strains fall within subclade III of the P. fluorescens species-complex. Our analysis reveals an extremely high degree of similarity between the clinical and environmental isolates; however, there are a number of genomic differences between the clinical and environmental subclade III strains, likely reflecting selective pressures unique in the CF lung.

\section{Results and discussion}

\section{Collection of $P$. fluorescens isolates}

The clinical strains of $P$. fluorescens described in this analysis were isolated over a seven-year period from respiratory samples collected at five different hospitals across the United States between March 2001 and January 2008. Six were isolated from adults with CF (five from sputum samples and one from a throat swab). One was isolated from an infant with CF (Table 1). Initial sequence-based analysis of the $16 \mathrm{~S}$ rRNA-encoding gene at the time of isolation was consistent with $P$. fluorescens and indicated that they were not $P$. aeruginosa (data not shown). Since each isolate came from different CF patients from five different hospitals across a seven-year period, each isolation likely represents a distinct bacterial strain.

\section{Phenotypic and growth properties}

The phenotypic and growth properties of the newly sequenced clinical strains were compared to those of a previously sequenced representative $P$. fluorescens strain, SBW25. The clinical strains all displayed phenotypic characteristics of bacteria within the P. fluorescens-species complex, e.g., motile, gram-negative, coccobacillus, lactose-fermentation negative, citrate growth positive, and fluorescence under ultra violet (UV) light (data not shown). While the clinical strains were phenotypically similar to the environmental strains in the above listed traits, they differed in their ability to grow at temperatures above $30{ }^{\circ} \mathrm{C}$. Environmental strains of $P$. fluorescens typically have an optimal growth range between 22 and $28{ }^{\circ} \mathrm{C}$ [1]. After $24 \mathrm{~h}$, all of the clinical strains were able to grow at $34{ }^{\circ} \mathrm{C}$ or higher in the laboratory, while the environmental subclade III strain SBW25 was unable to grow at this elevated temperature (data not shown). Other investigators have reported that human isolates of $P$. fluorescens have an increased temperature range for growth [1, 5-8], consistent with our observations. The

Table 1 Date, location and source of $P$. fluorescens strains

\begin{tabular}{llll}
\hline Isolate ID & Isolation Date & Isolation Location & Isolation Source \\
\hline AU2989 & $4 / 4 / 01$ & Hartford, CT & CF Throat Swab, Adult \\
AU6026 & $7 / 28 / 03$ & Seattle, WA & CF Sputum, Adult \\
AU10973 & $4 / 6 / 06$ & Salt Lake City, UT & CF Sputum, Adult \\
AU11518 & $7 / 12 / 06$ & Hartford, CT & CF Sputum, Infant \\
AU14440 & $10 / 19 / 07$ & Little Rock, AR & CF Sputum, Adult \\
AU14705 & $11 / 13 / 07$ & Augusta, GA & CF Sputum, Adult \\
AU14917 & $1 / 11 / 08$ & Little Rock, AR & CF Sputum, Adult \\
\hline
\end{tabular}

Date, location and source of clinical $P$. fluorescens subclade III strains. The newly sequenced strains were isolated over a seven year period, between March 2001 and Janurary 2008. Isolation occurred at five different hospitals across the United States. Each strain was isolated from a separate patient with CF 
newly sequenced clinical strains are able to grow at temperatures at or above $32{ }^{\circ} \mathrm{C}$ but otherwise show the same phenotypic and growth characteristics of previously studied strains of $P$. fluorescens.

\section{Genomic assembly}

The seven clinical $P$. fluorescens strains were sequenced on the Illumina HiSeq platform. Genomic DNA was prepared for each strain and the paired-end read sequences were partially de novo assembled using DNAstar's SeqMan NGen software. Assembly statistics of each of the newly sequenced strains are shown in Additional file 1: Table S1. Contigs were assembled into scaffolds. Average coverage across genome ranged from 44X (AU10973) to 68X (AU14705). As a methodologic control (sequencing and assembly), we also sequenced and de novo assembled SBW25, which was included in our subsequent analyses.

\section{Genomic features}

A summary of the genomic features of the $P$. fluorescens strains is shown in Table 2. Genome size of the clinical strains ranged between 6.1 megabase pairs (Mbps) and 6.88 Mbps. This is similar to the range seen in environmental strains (5.95 - 6.72 Mbps). The GC content per genome was also similar between clinical and environmental strains $(59.5$ - $60.8 \%$ versus 59.6 - $60.5 \%$, respectively). All of the $16 \mathrm{~S}$ rRNA gene sequences in the clinical strains were $>97 \%$ nucleotide identical to that found in P. fluorescens strain A506, with some being $>99 \%$ nucleotide identical (Additional file 2: Table S2).

\section{Phylogenetic analysis}

To classify the newly sequenced clinical strains, we utilized a multi-locus sequence analysis (MLSA) approach, modified from the scheme described by Loper et al. [3] (Fig. 1). All publically available genomes from the $P$. fluorescens species-complex, and some additional strains within the Pseudomonas genus, were included in the phylogenetic analysis. The diverse environmental sources of the fully sequenced $P$. fluorescens isolates have been summarized in a recent review [1]. In our analysis, the previously sequenced strains of $P$. fluorescens formed three distinct phylogenetic subclades within the tree, consistent with the initial publication of the phylogenetic analysis of these strains (Fig. 1) [3, 15].

All seven clinical strains were placed within subclade III of the P. fluorescens species - complex (Fig. 1). Strain AU6026, isolated from CF sputum in Seattle, WA (Table 1), segregated closest to environmental strain A506, which was taken from a leaf surface isolate in California [3]. Clinical strain AU10973, isolated from a patient in Salt Lake, UT in 2006, segregated closest with strain SBW25, isolated from a sugar beet in England. Two separate sub-branches within subclade III contained only clinical strains. AU14440, AU14917 and AU14705 branched together on one sub-branch while AU2989 and AU11518 branched together on a second, clinical-only sub-branch. Figure 1 presents the phylogenetic analysis of sequenced clinical strains of $P$. fluorescens alongside sequenced environmental strains.

Additional phylogenetic analysis of the clinical isolates was performed using average nucleotide identity (ANI) and unweighted pair group method with arithmetic mean (UPGMA) clustering (Fig. 2 and Additional file 3: Table S3). ANI uses the shared nucleotide identity between bacteria genomes to infer taxonomic relationships, where $95 \%$ is considered the cut-off for species delineation $[14,16]$. The percent ANI shared between members of subclade III ranged from 86 to $98.9 \%$ (Additional file 3: Table S3). The ANI between P. aeruginosa PAO1 (a Pseudomonas sp. not found in the P. fluorescens species complex) and every $P$. fluorescens subclade III strain was below $79 \%$. Both of these

Table 2 Genomic features of the $P$. fluorescens strains in this study

\begin{tabular}{|c|c|c|c|c|c|c|}
\hline & Genome Size (Mbp) & $\mathrm{G}+\mathrm{C}$ Content (\%) & \# of Contigs \& Scaffolds & \# of Coding Sequences & \# of RNAs & Plasmid \\
\hline AU2989 & 6.2 & 60.4 & 49 & 5569 & 58 & No \\
\hline AU6026 & 6.11 & 60 & 34 & 5427 & 67 & No \\
\hline AU10973 & 6.13 & 60.8 & 23 & 5499 & 61 & No \\
\hline AU11518 & 6.31 & 60.3 & 61 & 5684 & 63 & No \\
\hline AU14440 & 6.88 & 59.5 & 109 & 6123 & 71 & No \\
\hline AU14705 & 6.1 & 59.9 & 97 & 5379 & 69 & No \\
\hline AU14917 & 6.82 & 60.1 & 36 & 5592 & 68 & No \\
\hline A506 [3] & 5.96 & 60 & 2 & 5267 & 69 (tRNAs) & Yes (57.0) \\
\hline SBW25 [3] & 6.72 & 60.5 & 2 & 5921 & 66 (tRNAs) & No \\
\hline BG33R [3] & 6.29 & 59.6 & 4 & 5511 & 68 (tRNAs) & No \\
\hline SS101 [3] & 6.17 & 60 & 2 & 5374 & 68 (tRNAs) & No \\
\hline
\end{tabular}




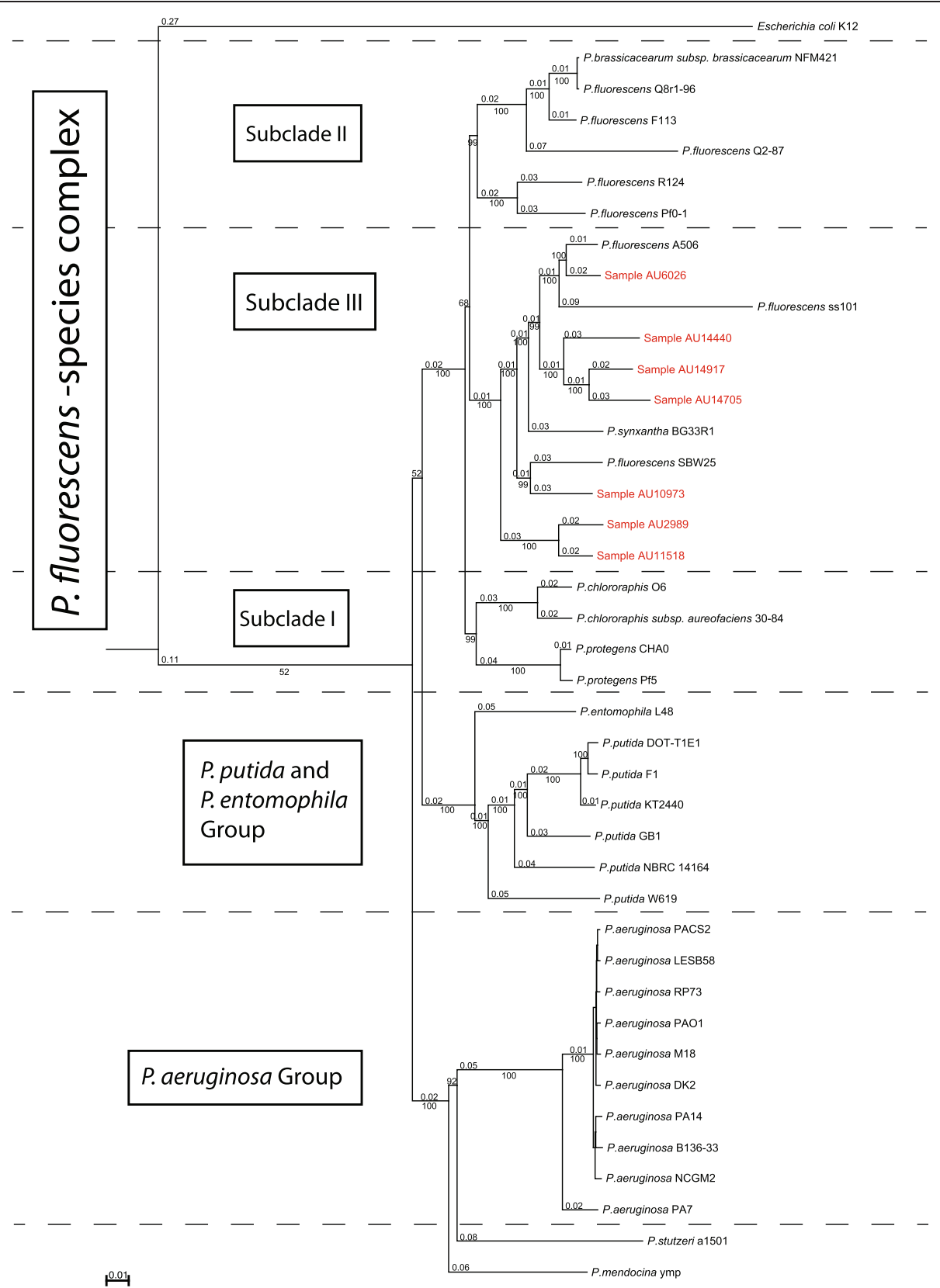

Fig. 1 Phylogenetic tree of the $P$. fluorescens strains in this study. Multi-locus sequence analysis of the following eight housekeeping genes was used to infer the phylogenetic tree: $d n a E$ (DNA polymerase III alpha subuit); ppsA (phosphoenolpyruvate synthase); recA (Recombinase A); rpoB (RNA polymerase subunit beta); gyrB (DNA gyrase subunit B); guaA (GMP synthease); mutL (DNA mismatch repair protein); pyrC (pyrimidine biosynthetic enzyme dihydroorotase) and acsA (acetyl-CoA synthetase). The concatenated sequences were aligned with MAFFT as described in the materials and methods. Clinical strains are highlighted in red [80, 81]

numbers corresponded to previously determined intraand inter-species shared ANI [4]. In summary, both MLSA and ANI analysis clearly revealed that each of the clinical strains belong within subclade III.

\section{Secondary metabolites}

Members of the P. fluorescens species-complex are welldocumented to produce numerous secondary metabolites necessary for living on plants and in the soil and rhizosphere [3]. The genetic sequence of every gene known to be involved in the production of the secondary metabolites listed in Table 3 was used to screen the newly sequenced clinical $P$. fluorescens strains using the standalone BLASTn function provided by NCBI [17] (Additional file 4: Table S4). The panel of genes involved in the production of secondary metabolites found in the 


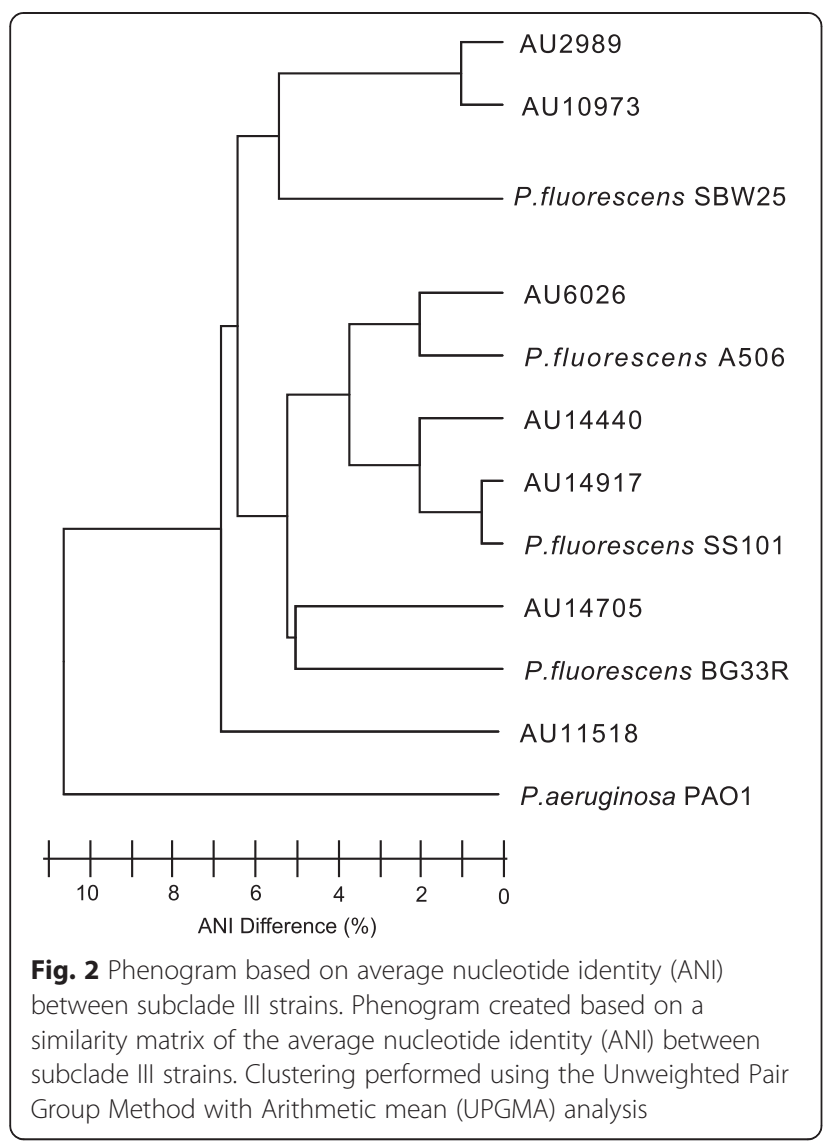

clinical strains agrees with what has been reported from previously sequenced $P$. fluorescens subclade III strains, in terms of presence, absence and variable presence [3]. None of the strains screened contained the genes necessary to make any of the seven P. fluorescens-associated antibiotics (Table 3). In contrast, every strain contained the full gene cluster to produce the siderophore pyoverdine $[18,19]$ (Table 3). In addition to the major siderophore pyoverdine, $P$. fluorescens strains produce multiple secondary siderophores. The genes necessary to produce the secondary siderophore, pseudomonine, were found in clinical strain AU14705 and environmental strains A506 and BG33R. Another secondary siderophore, hemophore, is involved in the chelation of heme from eukaryotic hosts [20]. The gene cluster required for the biosynthesis and efflux of this siderophore was found in clinical strains AU14705 and AU14917 and environmental strains SS101 and BG33R1. The environmental strains A506, SS101 and BG33R1 are all known to produce chitinase [3] (Table 3). Three clinical strains, AU6026, AU14705 and AU14917, also contained the gene cluster necessary to produce this enzyme. Every member of subclade III contained all four genes of the exoprotease AprA gene cluster. Our analysis revealed that clinically derived subclade III strains contain the secondary metabolite gene clusters known to be present in environmentally-derived subclade III strains.

\section{Pan, accessory, core genomes}

To determine the pan, accessory, and core genomes of the subclade III $P$. fluorescens strains, we calculated the number of clusters of orthologous groups of proteins (COGS) shared among the strains. On average, the strains in our study contained 5592 COGs per genome, with a range of 5332-6123. The pan genome, which includes all COGs, shared and unshared, among all the genomes, consisted of 11,795 individual COGs (Fig. 3). The core genome, which refers to only those COGs that are shared between all genomes, contained 3612 COGs (Fig. 3). The accessory genome, which is all the COGs not part of the core, contained 8183 individual COGs. Comparison of the genomes of the clinical strains and the environmental isolates revealed that they share the same general assortment of COGs. Clinical strains were found to have additional copies of COGs involved in metal-resistance, in particular, those of the $c z c$-gene family (Fig. 4a). Proteins produced through the $c z c$ gene cluster are important in regulating resistance to potentially toxic metals, such as zinc, copper, cobalt and cadmium, in gram-negative bacteria [21-25]. Though members of the $c z c$ gene family were also found in environmental strains, clinical strains had up to twice as many members of this gene family per genome (Fig. 4a). This suggested that either duplication or genetic transfer of the metal-resistance gene cluster occurred recently in the clinical strains. While the identity of the conserved protein families was the same across the subclade III genomes, COGs involved in metal resistance were found in significantly higher numbers in the clinical strains.

\section{Metal resistance genes}

Environmental strains contained on average 18 genes belonging to the $c z c$ gene cluster (range 17-19), while clinical strains contained on average $33 c z c$-related genes (range 23-47). The $c z c C B A$ gene cluster encodes for a resistance nodulation cell division (RND)type efflux pump that actively shuttles the metal cations out of the bacterial cell [26, 27]. The expressed CzcA protein constitutes the inner part of the of the RND efflux pump, and is a chemiosmotic cation/proton antiporter driven by a $\mathrm{H}+$ gradient $[26,27]$. Focusing on just the gene that encodes for the CzcA protein, environmental strains contained three $c z c A$ homologues each, while clinical strains contained between three and eight $c z c A$ homologues (Fig. 4a). To determine whether the presence of additional copies of the $c z c A$ gene was due to recent gene acquisition, the GC content across each $c z c A$ homologue was compared to the GC content across the entire genome of each strain. In the environmental strains, 
Table $\mathbf{3}$ Secondary metabolite genes and gene clusters in subclade III strains

\begin{tabular}{|c|c|c|c|c|c|c|c|c|c|c|c|c|c|}
\hline & & \multicolumn{7}{|c|}{ Antibiotics } & \multicolumn{5}{|c|}{ Siderophores } \\
\hline & & DAPG & $\mathrm{HCN}$ & Phenazine & Pyrrolnitrin & Rhizoxins & Pyoluteorin & Mupirocin & Pyoverdine & Pseudomonine & Enantio-pyochelin & Achromobactin & Hemophore \\
\hline \multirow{6}{*}{$\begin{array}{l}\text { Human- } \\
\text { associated } \\
\text { Isolates }\end{array}$} & AU2989 & & & & & & & & $x$ & & & & \\
\hline & AU6026 & & & & & & & & $x$ & & & & \\
\hline & AU10973 & & & & & & & & $x$ & & & & \\
\hline & AU11518 & & & & & & & & $x$ & & & & \\
\hline & AU14705 & & & & & & & & $x$ & $x^{*}$ & & & $x$ \\
\hline & AU14917 & & & & & & & & $x$ & & & & $x$ \\
\hline \multirow{5}{*}{$\begin{array}{l}\text { Environment- } \\
\text { associated } \\
\text { Isolates }\end{array}$} & SBW25 UM & & & & & & & & $x$ & & & & \\
\hline & P.fluorescens SBW25 & & & & & & & & $x$ & & & & \\
\hline & P.fluorescens A506 & & & & & & & & $x$ & $x$ & & & \\
\hline & P. fluorescens SS101 & & & & & & & & $x$ & & & & $x$ \\
\hline & P. synxantha BG33R1 & & & & & & & & $x$ & $x^{*}$ & & & $x$ \\
\hline
\end{tabular}


Table 3 Secondary metabolite genes and gene clusters in subclade III strains (Continued)

Exoenzymes Plant-Bacterial Communication

\begin{tabular}{l} 
Pupirocin \\
\hline$X$ \\
$X$
\end{tabular}




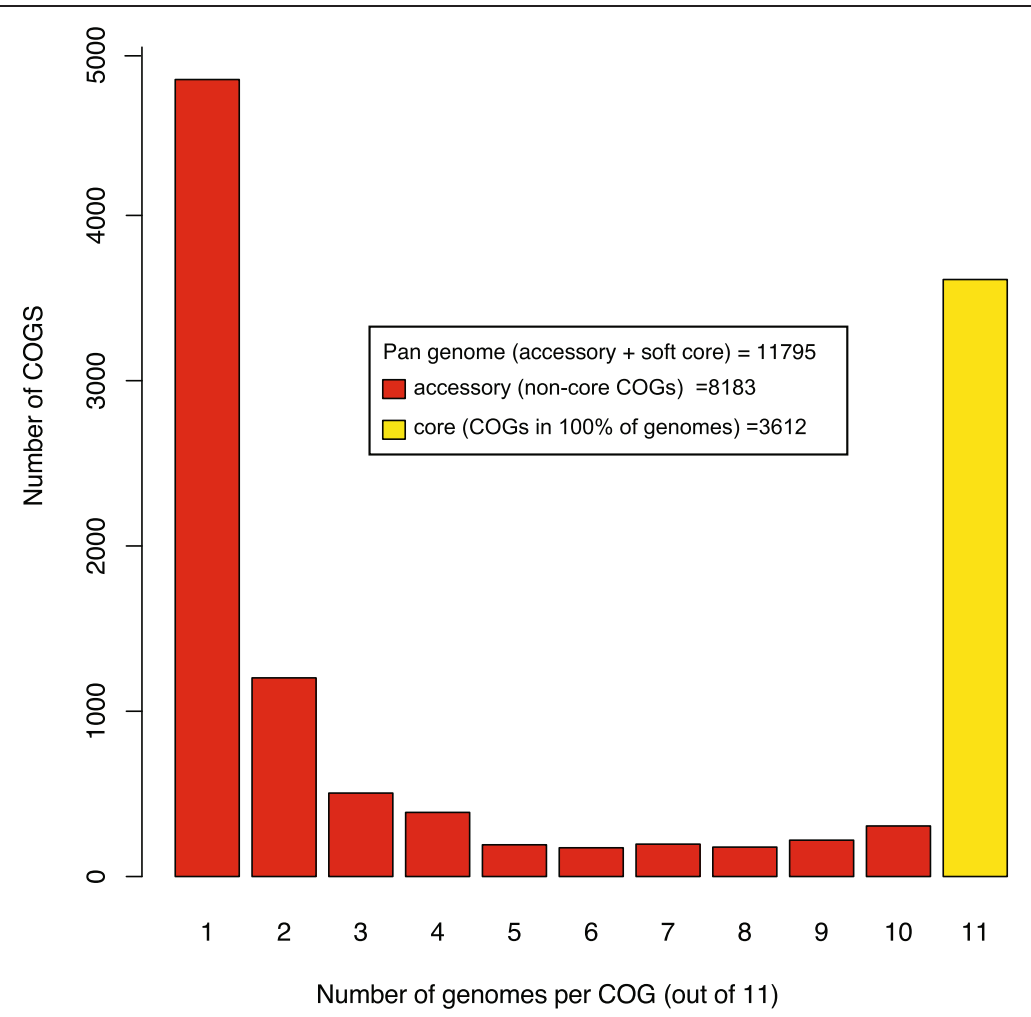

Fig. 3 The pan, accessory and core genomes in subclade III strains. Each of the 11795 COGS was analyzed to determine how many genomes encoded that particular COG (1-11, x-axis). Then the number of COGS encoded by only one genome, two genomes, etc. was determined (y-axis). The pan genome contains the accessory and core. The average number of COGs per genome is 5592 (range: 5332-6123). The pan genome and its compartments was calculated using the COGtriganle clustering algorithm in GET_HOMOLOGUES [82, 83]
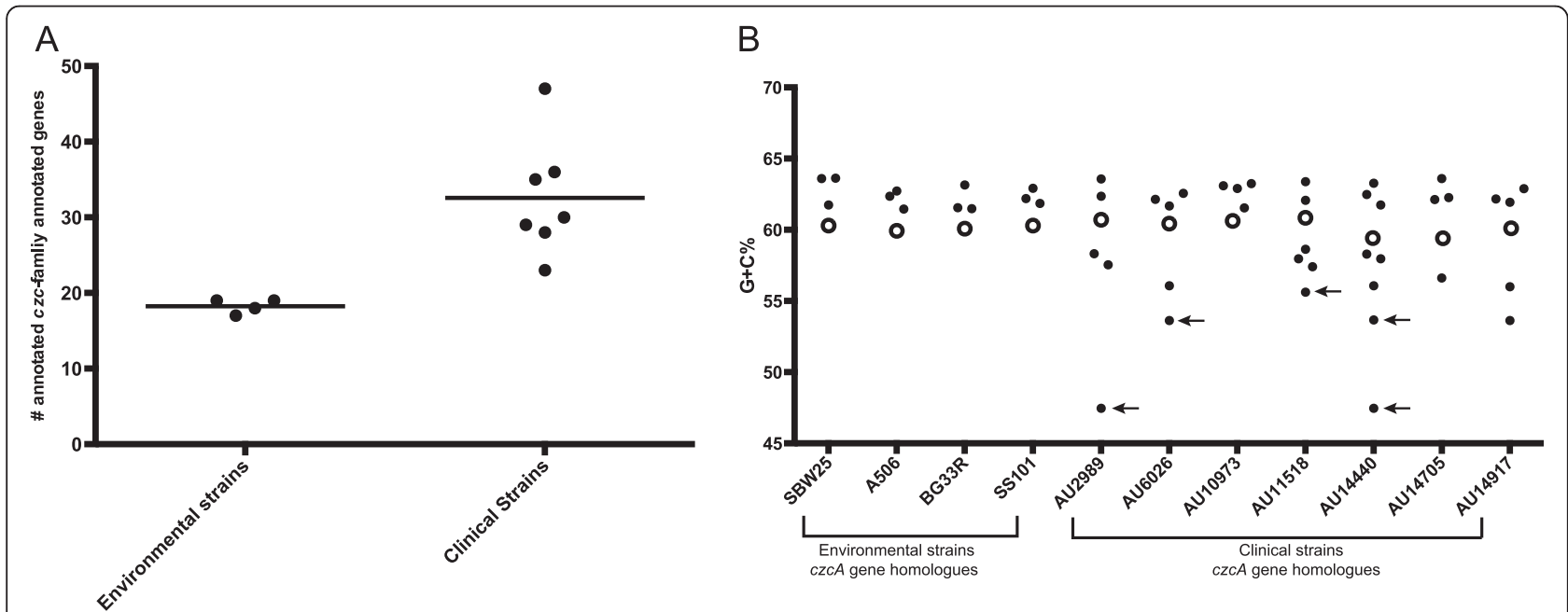

Fig. 4 The czc gene cluster in environmental and clinical subclade III strains. A. The total number of genes annotated as belonging to the $c z c A$ gene cluster in environmental and clinical subclade III strains. B. The percent $\mathrm{G}+\mathrm{C}$ content of the $c z c A$ gene homologues. Open circles correspond to the $\mathrm{G}$ $+C$ content found across the entire genome. Open circles correspond to the $G+C$ content found across the entire genome. Arrows indicate the $c z c A$ homologs enclosed in boxes in Fig. 5 


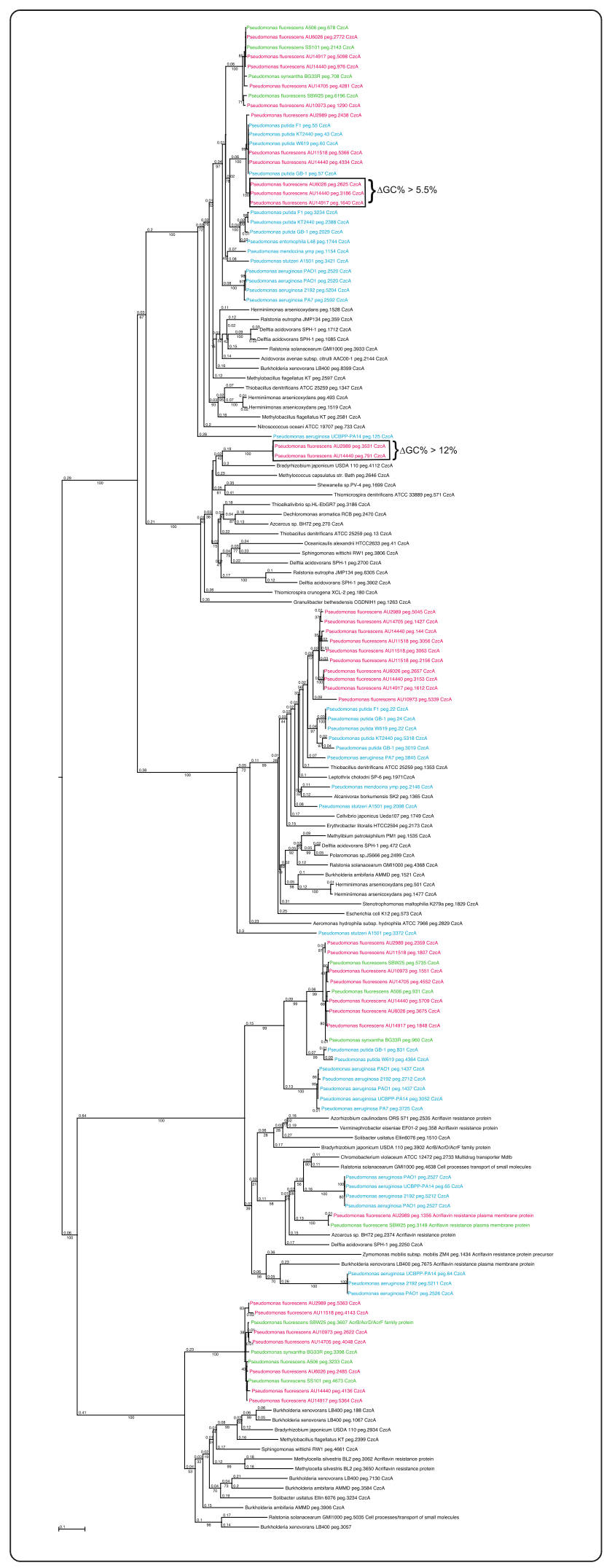

Fig. 5 Neighborhood-joining phylogenetic tree based on the amino acid sequence of CZCA homologues. CZCA homologues from clinical strains are highlighted in red; homologs from environmental strains are highlighted in green; homologues from other Pseudomonas spp. are highlighted in blue. Amino acid sequences of the proteins expressed from CZCA homologues discovered in RAST [78]. All other bacteria species are publically available on RAST. The amino acid sequences were aligned with MAFFT $[80,81]$

the $c z c A$ homologues had had similar GC content as that found across the entire genome (Fig. 4b). In contrast, in the clinical strains, there were $c z c A$ homologues that had significantly lower GC content than that found across the entire genome. Three $c z c A$ homologues (from AU6026, AU11518 and AU14440) had more than a $5.5 \%$ difference in GC content when compared to the entire genome, while two $c z c A$ homologues (from AU2989 and AU14440) had more than a $12 \%$ difference in GC content (Figs. 4b and 5). This level of difference in GC content suggests that these $c z c A$ gene clusters could represent recent events of horizontal gene transfer.

To further investigate whether the clinical strains gained additional $c z c A$ homologues through horizontal gene transfer, we built a phylogenetic tree containing the predicted amino acid sequences of the expressed CzcA proteins from clinical and environmental subclade III strains, as well as the amino acid sequences of representative Pseudomonas and non-Pseudomonas strains (Fig. 5). Each clinical strain had three CzcA homologues that grouped with the three CzcA homologues in the environmental strains (Fig. 5). Additionally, the clinical strains contained a CzcA protein whose most similar neighbor was the CzcA protein from $P$. putida. The proteins expressed from $c z c A$ gene homologues with significantly lower GC content are labeled on the tree. The three CzcA proteins expressed from genes with a GC content difference of more than $5.5 \%$ all grouped together in the tree, and are most closely related to the CzcA proteins from $P$. putida strains F1, KT2440 and GB-1, as well a CzcA protein from $P$. fluorescens A11518 and AU14440. The CzcA proteins expressed from $c z c A$ genes with more than $12 \%$ difference in GC content did not branch off with any CzcA homologue from a Pseudomonas strain, but instead, branched with a protein from Bradyrhizobium japonicum USDA110 (Fig. 5), further suggesting that these gene copies were acquired through recent horizontal gene transfer. Clinical subclade III strains contain homologues of $c z c A$ that show evidence of recent horizontal transfer from non-Pseudomonas bacteria strains. 


\section{GC islands}

We performed total and segmented GC content scans across the genomes of the newly sequenced clinical subclade III strains to look for genomic regions of recent horizontal gene transfer. The range in total GC content of the newly sequenced clinical strains (59.5 to $60.8 \%$ ) was similar to the range seen in the previously sequenced environmental strains (59.6 to $60.5 \%$ ) (Table 2). However, the segmented GC scans revealed genomic regions where the GC content dropped drastically from the overall average (Additional file 5: Figure S1). We referred to the regions of lower GC content as Lower GC Islands (LGCI) and those with more than a $15 \%$ difference from the overall genome GC average were selected for further investigation. We used the coordinates of the LGCIs provided by the GC-Profile tool to select the nucleotide sequence of the LGCI from each isolate's genome. This nucleotide region was then used to screen the non-redundant nucleotide database on NCBI with the online megablast function (http://blast.ncbi.nlm.nih.gov/ Blast.cgi). The results of the LGCI nucleotide screens are presented in Additional file 6: Table S5. The nucleotide screens revealed that some of the LGCIs are more genetically similar to Pseudomonas species outside of the $P$. fluorescens species-complex, suggesting regions of recent horizontal gene transfer into the clinical strains.

\section{The PfiT/I2 region}

Although PfiT/I2 has been identified as a P. fluorescensspecific immunostimulatory protein, no one has yet characterized the PfiT/I2 sequence in the genomes of fully sequenced $P$. fluorescens strains. The PfiT/I2 region of $P$. fluorescens encodes for an antigenic peptide (I2), which has superantigen properties and is highly associated with various enteric and autoimmune diseases [28]. To investigate differences at the amino acid level, we screened each subclade III strain using a local BLASTp search with the published PfiT amino acid sequence [29] and the top hit was selected from each genome to create a multiple protein sequence alignment (Fig. 6). The original published $P$. fluorescens $\mathrm{PfiT}$ protein sequence was used as a reference and the residues that differ from the reference were highlighted in the figure. Just 29 of the 208 amino acids (13.9\%) showed any variation between the strains. Seven of these amino acid changes were seen in just one of the subclade III strains. Most notably, two residues were altered in every strain: a threonine to an isoleucine at position 80 and a lysine to a glutamic acid at position 108. The PfiT protein was previously determined to belong to the TetR-family transcriptional regulators and none of the substitutions that occurred in the PfiT sequence from subclade III strains occurred in residues known to be important for DNA binding [28]. Thus, PfiT/I2 is highly conserved at the amino acid level in all the P. fluorescens strains analyzed in our study.

\section{Secretion systems \\ Type II secretion system}

The Type II secretion system (T2SS), also known as the general secretion (gsp) pathway, is a highly conserved secretion system within Gram-negative bacteria and is prevalent among gamma-proteobacteria $[30,31]$ and the

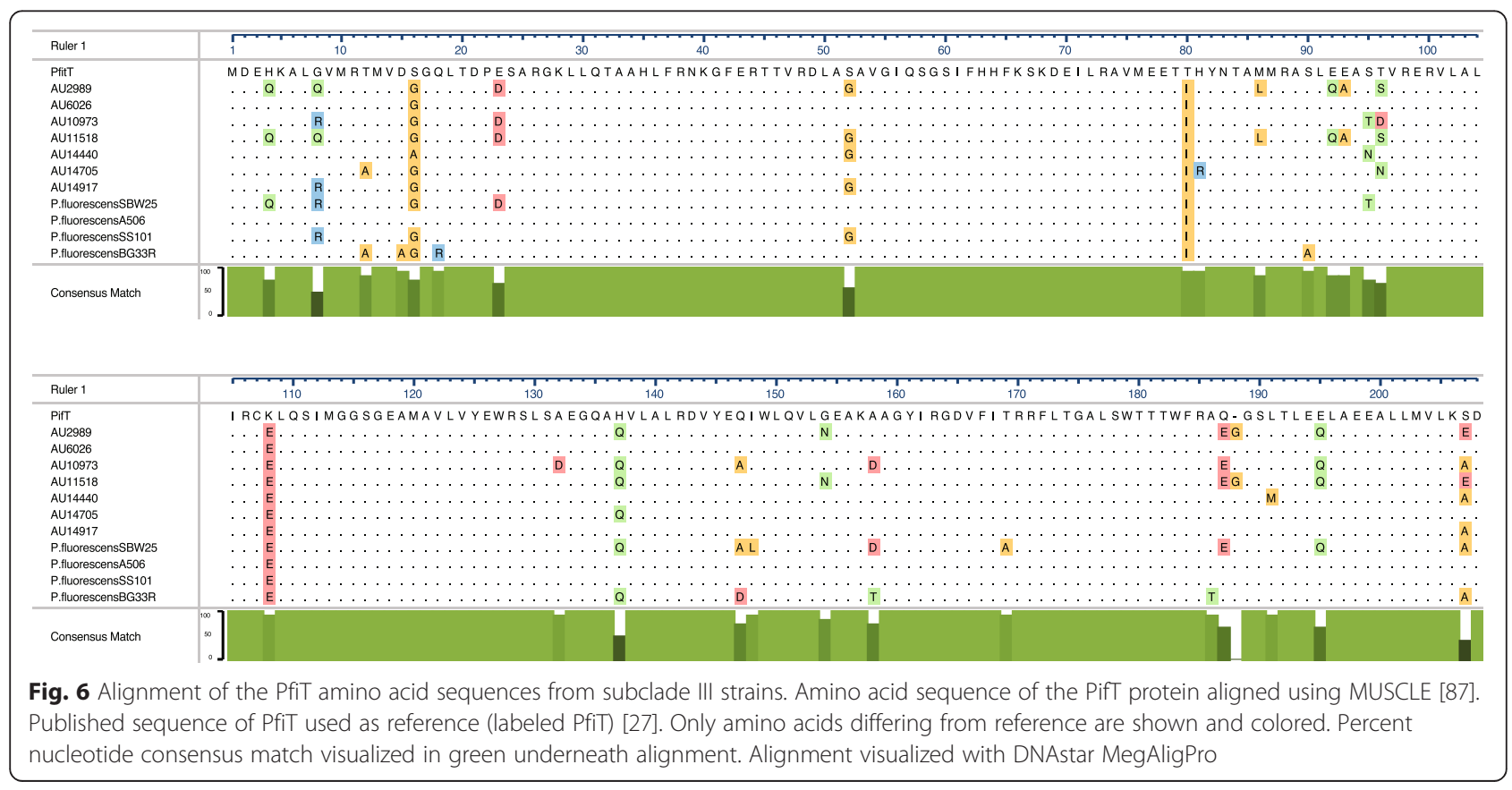


Pseudomonas genus [32]. The T2SS contains twelve core components: an outer membrane secretin (GspD); a cytoplasmic ATPase (GspE); an inner membrane protein (GspF); major (GspG) and minor (GspH, I, J, K) pseudopilins, proteins that assist with ATPase attachment to the inner membrane and form an inner membrane platform (GspL, M); a pre-pseudopilin peptidase/methyltransferase $(\mathrm{GspO})$ and a protein possibly involved in substrate recognition or secretion interactions (GspC) [30, 33]. Gamma-proteobacteria can contain either one [30], or multiple [34-36], set(s) of T2SS genes ( $g s p C D E F G H I J K L M O)$. Every subclade III strain but AU14440 contained between one and three T2SS gene clusters (Fig. 7 and Additional file 7: Table S6). These results agreed with what has been previously reported for T2SS gene clusters in subclade III strains [3]. Clinical strain AU14440 was missing five general secretion genes ( $g s p J K L M N)$. These missing genes are necessary for the standard pilus structure of the T2SS [30, 33] and, therefore, AU14440 likely does not contain the standard typeII secretion system found in other P. fluorescens strains.

\section{Type III secretion system}

Type-III secretion systems (T3SS) are needle-like structures that bacteria use to deliver effector proteins directly into nearby host cells [37]. T3SSs fall into multiple families based on the genetic structure and the macromolecular structure of the needle complex. The Hrp1 T3SS [38] is the most common T3SS found in the $P$. fluorescens species-complex [3, 39-42]. The environmental subclade III strains SBW25, BG33R, A506, SS101, and the subclade II strains Q8r1-96 and Q2-87, all contained at least one copy of a Hrp1 family T3SS [3]. However, this system was not found in all P. fluorescens strains, as both PfO- 1 and Pf- 5 did not have an
Hrp1 T3SS gene cluster [3, 43]. A list of the genes annotated as belonging to the Hrp1 T3SS in the subclade III P. fluorescens strains is reported in Fig. 7, with the full annotated gene name shown in Additional file 7: Table S6. The genes $h r p D, h r p G, h r p Q$ and $h r p T$ all vary in whether or not they are included in the Hrp1 T3SS gene cluster. Environmental strain SBW25 has been reported to contain a functional T3SS [44], even though our analysis shows that it lacks $h r p D$ and $h r p Q$, suggesting these two genes are not required for T3SS function. Whether or not HrpG and HrpT are required cannot be concluded until the functionality of a T3SS in additional subclade III strains is tested. Genes related to the Hrp1 T3SS were found in each of the subclade III strains analyzed. In summary, this is the first report demonstrating that the genomes of clinically-isolated strains of $P$. fluorescens encode for a T3SS.

\section{Type-IV secretion system}

In $P$. aeruginosa, the T4SS genes pilABCDEFGHIJKLMNOPQRSTUVWXY1Y2Z are required for twitching motility [45] and the subclade III strains analyzed here were missing between one and seven of the T4SS genes required for twitching motility in P. aeruginosa (Fig. 7 and Additional file 7: Table S6). The Type-IV secretion system (T4SS), also known as the Type-IV pili or fimbria, is a three-dimensional filament on the surface of bacteria that is important in adhesion, protease secretion and motility [46]. As was seen in the T2SS gene cluster (Fig. 7 and Additional file 7: Table S6), AU14440 was missing the largest number of T4SS-associated genes, lacking homologues to pilBDGHLRT and the genes that encode for the adhesins, FimA and FimD. Due to the large number of T4SS gene homologues missing in AU14440, it is likely that this isolate does not contain a functional

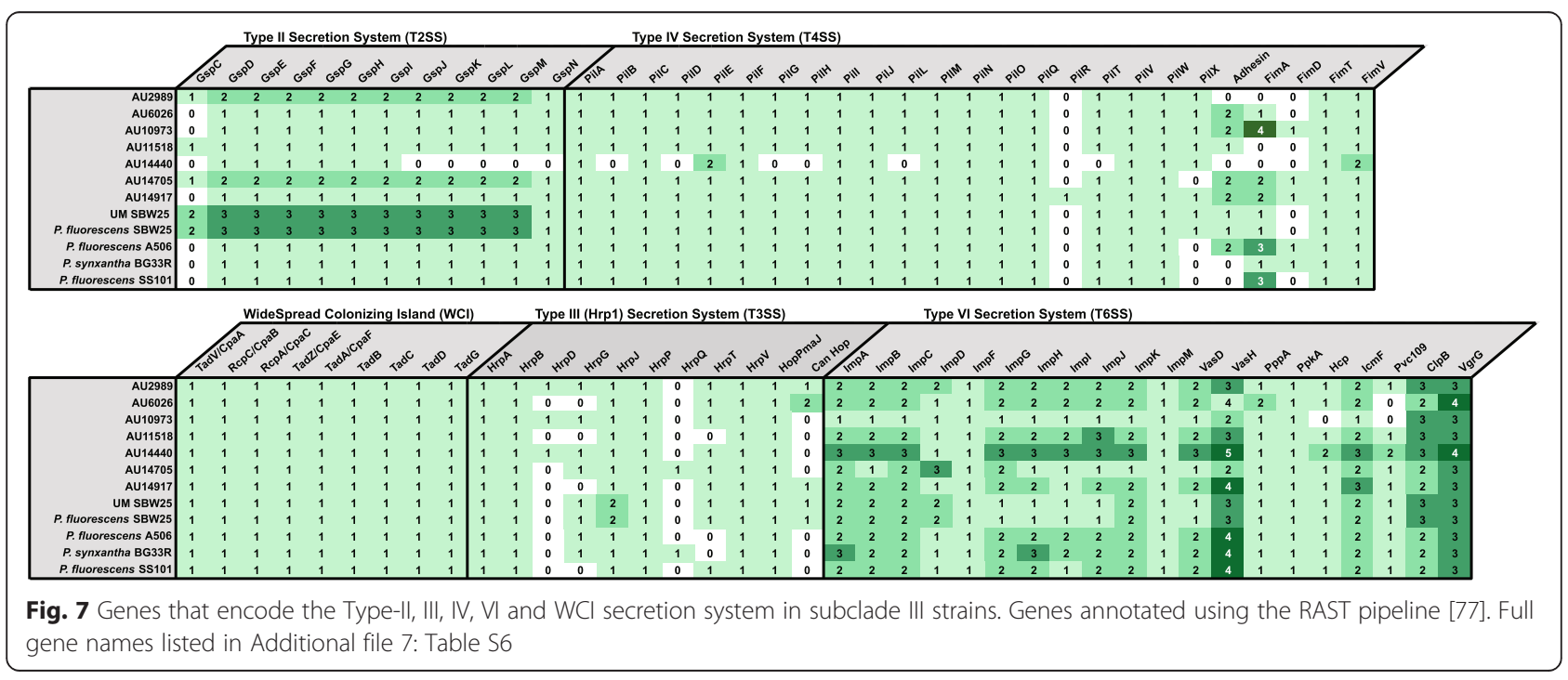


T4SS. The number of gene homologues for the T4SS proteins adhesin, FimA and FimD, varied considerably between the subclade III strains. FimA, a type IV fimbria major subunit protein, shows the largest variation in gene homologues per genome, ranging from none (AU2989, AU11518 and AU14440) to four per genome (AU10973). Thus, every clinical subclade III strain contained a majority of the genes known to be required for twitching motility in $P$. aeruginosa, with the strain AU14440 missing the highest number of T4SS related genes.

We further analyzed the fimA genes from a sample group of subclade III strains (Additional file 8: Figure S2). We aligned the genetic sequences of fimA from A506, AU6026 and AU10973 using the MAFFT algorithm (Additional file 8: Figure S2). The alignment revealed that the genes annotated as $\operatorname{fim} A$ fall into two major groups: fimA 'a' group and fimA 'b' group. Subclade III strains A506 and AU10973 contained fimA homologues in both these two genetic groups. In addition, A506 and AU10973 both contained fimA homologues that fell within the same group but varied by single point mutations. This analysis revealed that $P$. fluorescens subclade III strains contained multiple homologues of the fimA gene and homologues can vary by point mutations along the sequence. As the fim $A$ gene has only been annotated in a select number of Pseudomonas spp. (http:// www.pseudomonas.com/) it is not possible to know if this level of redundancy is seen across the $P$. fluorescens species-complex or the rest of the Pseudomonas genus. Further analysis is required to understand the function of multiple fimA genes in the subclade III strains.

\section{Widespread Colonizing Island (WCI) / tad locus}

The WCI has not previously been studied in P. fluorescens. Due to its importance in colonizing new environmental niches, the locus containing the tad genes is referred to as the 'widespread colonization island' (WCI) [47]. The tad locus is a newly described subtype of type II secretion system [48]. Proteins expressed by the tad locus are important for biofilm formation and colonization of hosts in multiple bacterial species. In $P$. aeruginosa, the genes within the $\mathrm{WCI}$ are regulated by the same quorum sensing circuit that regulates multiple virulence factors $[49,50]$. All subclade III strains contained the ten WCI-associated genes: $c p a A B C E$ and tadABCDG (Fig. 7). Based on the presence and order of the genes in the tad locus, the $P$. fluorescens subclade III strains analyzed in this study can be predicted to encode a functional WCI.

\section{Type VI secretion system}

Here we surveyed the Type- IV secretion system (T6SS) across the subclade III strains, and found that each strain carried between 1-3 T6SS gene clusters (Fig. 7).
The T6SS is a macromolecular complex that either transports bacterial effectors directly into target cells or releases them into the extracellular medium [51]. Many of the T6SS genes found in the P. fluorescens strains are highly conserved across all bacterial strains that contain a T6SS [52] (Fig. 7 and Additional file 7: Table S6). Every $P$. fluorescens strain within this analysis contained at least one copy of impABCDGHIJK, vasDH, $p p A, p p K \mathrm{~A}$, $\operatorname{dot} U$, icmF, $\operatorname{clp} B, \operatorname{clpV1}$, vgrG1 and $v g r G 2$ genes. It has been reported that at least 11 structural proteins and two effector proteins (mainly Hcp and VgrG) are required to assemble a functional T6SS $[52,53]$. Each subclade III strain also contained multiple copies of the effector proteins Hcp and VgrG. Multiple copies of effector proteins are thought to be tied to the multiple utilizations of the T6SS within a bacterial cell, allowing a bacterium to differently utilize the T6SS depending on environmental conditions [53]. The newly- sequenced human-associated subclade III strains contained multiple copies of the structural T6SS genes, and a large number of T6SS effectors, similar to what has been reported in other P. fluorescens strains.

The number of vasH homologues annotated in the subclade III strains ranged from two (AU10973 and AU14705) to five (AU14440). VasH is a sigma-54 dependent transcriptional regulator that has been shown to regulate transcription of the T6SS [54-56]. The sigma factor 54 is an alternate sigma factor that functions as a global regulator in multiple plant and animal associated bacteria $[57,58]$. Sigma factor 54 interacts with RNApolymerase and a sigma-54 dependent transcriptional regulator (such as VasH) to initiate transcription at sigma-54 dependent promoters $[58,59]$. In order to investigate the differences between these $v a s H$ gene homologues, we did a multiple sequence alignment of the vasH genes from A506, AU6026, AU10973 and AU14440 and assembled a phylogenetic tree (Additional file 9: Figure S3). The separate $v a s H$ homologues fell into four separate groups based on nucleotide sequence similarity, labeled as groups 'a, 'b', 'c' and 'd'. The vasH 'a' homologues showed the highest similarity to the vasH from Vibrio cholera. AU14440 also contained an additional copy of a vasH homologue that branches with the Vibrio cholera vasH. AU10973 also has two copies of a vasH homologue, one in branch 'c', and one in branch ' $d$ '. This analysis revealed that the different homologues of vasH fell within distinct evolutionary groups based on nucleotide similarity comparison.

\section{Conclusions}

We present the first comparative genomic analysis of Pseudomonas fluorescens isolates from clinical samples. Previously, all sequenced $P$. fluorescens strains had been isolated from environmental samples, such as the soil, 
plant leaves and loam [1, 3]. Comparing the genome of seven strains of $P$. fluorescens isolated from the lungs of individuals with CF (Table 1) to four previously sequenced environmental strains within the same subclade (III), we found that all eleven strains were very similar in regard to global and individual genomic features (Tables 2 and 3; Fig. 6). However, the clinical strains analyzed in this study differed from the environmental strains in two important ways. Firstly, the strains isolated from clinical samples had an increased temperature growth range that allowed them to grow between $32{ }^{\circ} \mathrm{C}$ and $37^{\circ} \mathrm{C}$, while the representative environmental strain SBW25 could not grow above $28{ }^{\circ} \mathrm{C}$. The finding that the clinical isolates studied in this paper can grow at $32{ }^{\circ} \mathrm{C}$ or higher agrees with other accounts of strains of $P$. fluorescens isolated from mammalian samples [5-8]. Changes in temperature often signal a change in environmental context, and bacteria have multiple mechanisms to sense these changes, including signaling through two-component sensor (TCS) systems [60]. It remains to be determined whether differences in a specific TCS may account for this difference.

The clinical strains also differed significantly from environmental strains in the number of protein-coding genes involved in the resistance nodulation cell division (RND)type of efflux pump that regulates zinc, cadmium and cobalt ions in many gram-negative bacteria [24, 26, 61]. Efflux pumps control the concentration of metal ions that pass through a bacterial cell and there is strong evidence for a link between resistance to metal ions and antibiotics $[61,62]$. Metals, such as zinc, are necessary for bacterial growth in trace amounts. However, when in abundance, metal cations become toxic to the bacterial cell. Zinc will bind to free thiol groups, which can disrupt protein function [63]. The RND-type efflux pump produced by the CzcCBA proteins is regulated by the CzcR-S twocomponent system [26]. In P. aeruginosa, treatment with zinc leads to the expression of the $c z c R S$ operon, which then leads to transcriptional activation of $c z c C B A$ [61]. There is a link between the metal resistance conferred through the $c z c C B A$ efflux pump and resistance to antibiotics, such as imipenem. The same two-component regulator that turns on transcription of $c z c C B A$ also negatively regulates the gene oprD. This gene encodes for the specific porin, OprD, which is the primary route by which carbapenems, such as impienem, enter into a bacterial cell [62]. In laboratory conditions, exposure to zinc can lead to spontaneous mutations in the $c z c S$ sensor gene in $P$. aeruginosa, making the bacteria resistant to imipenem exposure [61]. Increased resistance to antibiotics has been seen in multiple different metal-contaminated environments, such as freshwater streams [64], costal areas [65], and metal-contaminated ash settling basins [66]. GC content and phylogenetic analysis of the $c z c A$ gene involved in zinc, cadium and cobalt resistance suggested that clinical strains obtained additional copies through horizontal gene transfer from bacteria outside of the Pseudomonas genus.

Our findings that the clinical strains were highly similar to environmental strains within the same phylogenetic subclade is in itself significant because it highlights that many of the qualities that $P$. fluorescens bacteria utilize to succeed in the environment also benefit survival in a human host. Environmental and clinical strains of P. aeruginosa are often very similar genomically $[67,68]$, with a few notable differences that include increased temperature growth range [69] and the acquisition of additional antibiotic resistance traits [70-74]. The clinical strains analyzed in our current study all fell into subclade III of the $P$. fluorescens species complex; further studies will likely that reveal clinical strains of $P$. fluorescens in each of the phylogenetic divisions. The very definition of an "environmental", "clinical" or "human" strain is in fact an artificial construct; bacteria will colonize and persist in any niche that provides the requirements necessary for growth. As more clinical strains of $P$. fluorescens are discovered, sequenced and analyzed, our understanding of what genetic attributes are important for the various lifestyles of $P$. fluorescens in its different niches is likely to expand and become more refined.

\section{Methods}

\section{Strain isolation, storage and 165 typing}

The seven $P$. fluorescens strains were isolated between March 2001 and January 2008, from five hospitals across the United States (Hartord, CT; Seattle, WA; Salt Lake City, UT; Little Rock, AR; Augusta, GA, Table 1). The majority (six strains) were isolated from sputum; one strain was isolated from a throat swab. One strain was isolated from an infant with CF. P. fluorescens SBW25 was kindly provided by Dr. Stuart Levy (Tufts University). Isolates were banked and stored at $-80 \mathrm{C}$. The universal primer set $8 \mathrm{~F}$ and 1492R [75] was used to amplify a portion of the $16 \mathrm{~S}$ rRNA gene through PCR, which was then Sangersequenced using an ABI 3730XL sequencer. Partial 16S sequences were screened through NCBI's nonredundant nucleotide database and identified as P. fluorescens. Individual strains were either streaked out on LB agar for phenotypic assays or grown up aerobically overnight in Luria Broth at $34{ }^{\circ} \mathrm{C}$ for DNA isolation.

\section{Phenotypic assays}

To determine the temperature range for growth, a single colony was selected from an agar plate and grown in Luria Broth aerobically for $18 \mathrm{~h}$ at room temperature $\left(22^{\circ} \mathrm{C}\right)$, $34{ }^{\circ} \mathrm{C}$ and $37^{\circ} \mathrm{C}$. The optical density at $600 \mathrm{~nm}$ was measured and compared to non-inoculated broth. Plates were incubated at $34{ }^{\circ} \mathrm{C}$ for twenty-four hours and colony forming were counted and used to calculate doubling time. 
All phenotypic assays were performed from a single colony grown up from an $-80{ }^{\circ} \mathrm{C}$ glycerol stock maintained in the lab. Fluorescence was assayed using an UV light. Standard Gram-stain was used to determine whether each strain was gram-negative or positive. Motility was assayed by looking for movement on a wet mount under 100x magnification.

\section{DNA isolation}

Genomic DNA was extracted from $2 \mathrm{~mL}$ of overnight culture growth using the DNeasy Blood and Tissue Kit (Qiagen Cat\# 69506) following manufacturer's recommendations.

\section{Genome sequencing, assembly and annotation}

Whole genome sequencing was performed at the University of Michigan Sequencing Core on the Illumina HiSeq 2000 platform with a 100-bp paired-end library. Illumina reads were assembled de novo with the DNAstar SeqMan NGen Version 12 software. The seven genomes were assembled into contigs and contigs were ordered with the Mauve aligner 'reordering contigs' function [76] using a previously sequenced $P$. fluorescens subclade III genome (A506) as a reference. Annotation was performed using the automated online software RAST [77, 78]. The presence or absence of secondary metabolite genes was assayed through the BLASTn function provided by NCBI [17] using a chosen query sequence listed in Additional file 4: Table S4 and a cutoff of evalue $<1 \mathrm{e} 15$ and sequence identity $>70 \%$ [79].

\section{Nucleotide sequence accession numbers}

The draft genomes have been deposited at DDBJ/EMBL/ GenBank with accession numbers JRXT00000000, JRXU00000000, JRXV00000000, JRXW00000000, JRXX00000000, JRYA00000000, JRXY00000000, for isolates AU2989, AU6026, AU10973, AU11518, AU14440, AU14705, AU14917, respectively.

\section{MLSA and phylogenetic analysis}

Multi-locus sequence analysis was performed using the concatenated sequences of the following housekeeping genes- dnaE, ppsA, recA, rpoB, guaA, mutL, pyrC and acsA-modified from the approach in Loper et al. [3]. The nucleotide sequences of the $c z c A$ homologues were discovered in RAST and used to infer a phylogenetic tree. The sequences used to construct the MLSA and $c z c A$ homologue phylogenetic trees were aligned using MAFFT $[80,81]$ and the trees were inferred using a neighborhood-joining method with 1000 bootstraps. Shared average nucleotide identity (ANI) was determined using the online software at http://enve-omics.ce.gatech.edu/ani [14]. A similarity matrix of the ANI between the subclade III strains was created and clustering performed using the Unweighted Pair Group Method with Arithmetic mean (UPGMA) algorithm.

\section{Pan, accessory and core genome and GC analysis}

The pan, accessory and core genomes were calculated using the COGtriangle algorithm [82] in GET_HOMOLOGUES [83]. The COG algorithm detects candidate sets of orthologous proteins, with the given requirement that included proteins are also found in at least three evolutionarily distant species [84, 85]. Each protein represented by a COG is therefore thought to have evolved from a single ancestral gene [84]. GC island content and islands were calculated using the online $\mathrm{GC}$ profile tool at http://tubic.tju.edu.cn/GC-Profile/ [86]. The GCProfile tool segments an inputted genome based on parameters provided by the user and provides the GC content across the genome segments, as well as the cumulative GC content of the entire genome.

\section{Analysis of individual genes}

The amino acid sequence of PfiT from subclade III strains was aligned using MUSCLE [87]. Alignment of the fimA nucleotide acid homologues was performed using the MAFFT algorithm [80, 81]. The nucleotide sequences of $v a s H$ homologues were aligned in Mauve [88]. The PfiT, fimA and vasH alignments were visualized using DNAstar's MegaAlignPro software.

\section{Availability of supporting data}

The data sets supporting the results of this article are available in the NCBI whole genome repository at http://www.ncbi.nlm.nih.gov/genome/.

\section{Ethics statement}

The bacterial samples in this study were exempt from ethics approval: they were provided by clinical microbiology labs, as de-identified cultures, with all patient identifiers removed.

\section{Additional files}

Additional file 1: Table S1. Assembly statistics of the $P$. fluorescens strains in this study. The paired end reads from Illumina HiSeq were de novo assembled using the DNAstar SeqMan NGen. (PDF $387 \mathrm{~kb}$ )

Additional file 2: Table S2. The nucleotide sequence of the 165 rRNA sequences was used to query the NCBI nucleotide collection (nr/nt). (PDF $170 \mathrm{~kb})$

Additional file 3: Table S3. Average nucleotide identity (ANI). Shared average nucleotide identity between each strain in subclade III was determined using the online tool at http://enve-omics.ce.gatech.edu/ani [14]. Values presented in $\%$ shared ANI and $\geq 95 \%$ shadowed in gray. (PDF $370 \mathrm{~kb}$ )

Additional file 4: Table S4. Secondary metabolite genes and reference organism for BLAST. Each gene involved in the production of the secondary metabolites analyzed in Table 3 is listed in the left column. The source organism of each gene's nucleotide sequence used for the 
blast search is in the middle column. The NCBI ID for each source organism is the right column. (PDF $54 \mathrm{~kb}$ )

Additional file 5: Figure S1. GC content calculated using the online GC profile tool [86]. GC content displayed on $y$-axis and position in draft genome displayed on $\mathrm{x}$-axis. Arrows indicate GC islands that have been further analyzed via NCBI BLASTn, results in Additional file 6: Table S5. (PDF $559 \mathrm{~kb}$ )

Additional file 6: Table S5. BLAST results of selected GC Islands. The nucleotide sequences of selected GC Islands (indicated with arrows in Additional file 5: Figure S1) were used to query the NCBI nucleotide collection (nr/nt). The top six results are displayed. (PDF $48 \mathrm{~kb}$ )

Additional file 7: Table S6. Full annotation of genes involved in secretion systems in subclade III strains. Abbreviations on left correspond to those found in Fig. 7 of paper. Fully annotated gene names are in the right column, as provided by the RAST annotation pipeline [78]. (PDF $47 \mathrm{~kb}$ )

Additional file 8: Figure S2. Alignment of fimA homologues from select environmental and clinical subclade III strains. fimA homologues defined in RAST [78]. Nucleotide sequence of fimA homologues aligned with the MAFFT algorithm within DNAstar's MegAlign Pro software. A506 is a representative environmental strain; AU6026 and AU10973 are representative clinical strains. (PDF $1267 \mathrm{~kb}$ )

Additional file 9: Figure S3. Phylogenetic tree inferred from the nucleotide acid sequences of vasH homologues from representative environmental and clinical subclade III strains. Mauve algorithm used for alignment [88]. A506 is a representative clinical strain; AU6026, AU10973, AU14440 are representative clinical strains. (PDF $346 \mathrm{~kb}$ )

\section{Abbreviations}

P. fluorescens: Pseudomonas fluorescens; CF: Cystic fibrosis; MLSA: Multi-locus sequence analysis; T3SS: Type III secretion system; UV: Ultra violet; ANI: Average nucleotide identity; UPGMA: Unweighted pair group method with arithmetic mean; COGS: Clusters of orthologoups groups; RND: Resistance nodulation cell division; GCl: GC Islands; T2SS: Type II secretion system; gsp: general secretion pathway; Hrp1: Hypersensitive response in plants; T4SS: Type IV secretion system; WCI: Widespread colonization island; T6SS: Type VI secretion system.

\section{Competing interests}

The authors declare that they have no competing interests.

\section{Authors' contributions}

Initial collection and culturing of the strains was performed by $J L$ and his laboratory. Phenotypic analysis, culture and DNA preparation was performed by BS. Bioinformatics was performed by BS, JE, IH and GH. Study design was conceived by GH, JL and BS. BS and GH wrote the initial draft of the manuscript and all authors contributed to its final version. All authors read and approved the final manuscript.

\section{Acknowledgements}

The authors wish to thank Nicole Falkowski, Rod McDonald and Chinmay Pandit for their technical contributions to this project. This study was funded in part by the following grants: NHLBI ROI-HL114447, NIAID U19-AI090871, Nesbitt Program for CF Research (UM) and University of Michigan HostMicrobiome Initiative. In addition, BS was supported in part by NIAID T32Al007528. The funding organization did not play any role in the design, analysis or interpretation of the data, the writing of the manuscript, or decision to submit the manuscript for publication.

\section{Author details}

'Division of Pulmonary and Critical Care Medicine, Department of Internal Medicine, University of Michigan Medical School, Ann Arbor, MI, USA. ${ }^{2}$ Department of Microbiology and Immunology, University of Michigan Medical School, Ann Arbor, MI, USA. ${ }^{3}$ Department of Pediatrics and Communicable Diseases, University of Michigan Medical School, Ann Arbor, MI, USA.

Received: 5 June 2015 Accepted: 30 November 2015

Published online: 07 December 2015

\section{References}

1. Scales BS, Dickson RP, LiPuma JJ, Huffnagle GB. Microbiology, genomics, and clinical significance of the Pseudomonas fluorescens species complex, an unappreciated colonizer of humans. Clin Microbiol Rev. 2014;27(4):92748. doi:10.1128/CMR.00044-14.

2. Silby MW, Cerdeno-Tarraga AM, Vernikos GS, Giddens SR, Jackson RW, Preston GM, et al. Genomic and genetic analyses of diversity and plant interactions of Pseudomonas fluorescens. Genome Biol. 2009;10(5):R51. doi: 10.1186/gb-2009-10-5-r51.

3. Loper JE, Hassan KA, Mavrodi DV, Davis 2nd EW, Lim CK, Shaffer BT, et al. Comparative genomics of plant-associated Pseudomonas spp.: insights into diversity and inheritance of traits involved in multitrophic interactions. PLoS Genet. 2012;8(7):e1002784. doi:10.1371/journal.pgen.1002784.

4. Mulet M, Lalucat J, Garcia-Valdes E. DNA sequence-based analysis of the Pseudomonas species. Environ Microbiol. 2010;12(6):1513-30. doi:10.1111/j. 1462-2920.2010.02181.x.

5. Chapalain A, Rossignol G, Lesouhaitier O, Merieau A, Gruffaz C, Guerillon J, et al. Comparative study of 7 fluorescent pseudomonad clinical isolates. Can J Microbiol. 2008;54(1):19-27. doi:10.1139/w07-110.

6. Donnarumma G, Buommino E, Fusco A, Paoletti I, Auricchio L, Tufano MA. Effect of temperature on the shift of Pseudomonas fluorescens from an environmental microorganism to a potential human pathogen. Int J Immunopathol Pharmacol. 2010;23(1):227-34.

7. Rossignol G, Sperandio D, Guerillon J, Duclairoir Poc C, Soum-Soutera E, Orange N, et al. Phenotypic variation in the Pseudomonas fluorescens clinical strain MFN1032. Res Microbiol. 2009;160(5):337-44. doi:10.1016/j. resmic.2009.04.004.

8. Sperandio D, Decoin V, Latour X, Mijouin L, Hillion M, Feuilloley MG, et al. Virulence of the Pseudomonas fluorescens clinical strain MFN1032 towards Dictyostelium discoideum and macrophages in relation with type III secretion system. BMC Microbiol. 2012;12:223. doi:10.1186/1471-2180-12-223.

9. Madi A, Lakhdari O, Blottiere HM, Guyard-Nicodeme M, Le Roux K, Groboillot A, et al. The clinical Pseudomonas fluorescens MFN1032 strain exerts a cytotoxic effect on epithelial intestinal cells and induces Interleukin-8 via the AP-1 signaling pathway. BMC Microbiol. 2010;10: 215. doi:10.1186/1471-2180-10-215.

10. Madi A, Svinareff P, Orange N, Feuilloley MG, Connil N. Pseudomonas fluorescens alters epithelial permeability and translocates across Caco-2/TC7 intestinal cells. Gut Pathog. 2010;2(1):16. doi:10.1186/1757-4749-2-16.

11. Sperandio D, Rossignol G, Guerillon J, Connil N, Orange N, Feuilloley $M G$, et al. Cell-associated hemolysis activity in the clinical strain of Pseudomonas fluorescens MFN1032. BMC Microbiol. 2010;10:124. doi:10.1186/1471-2180-10-124.

12. Dickson RP, Erb-Downward JR, Freeman CM, Walker N, Scales BS, Beck $J M$, et al. Changes in the lung microbiome following lung transplantation include the emergence of two distinct Pseudomonas species with distinct clinical associations. PLoS One. 2014;9(5):e97214. doi:10.1371/journal.pone.0097214.

13. van Passel MW, Kuramae EE, Luyf AC, Bart A, Boekhout T. The reach of the genome signature in prokaryotes. BMC Evol Biol. 2006;6:84. doi:10.1186/ 1471-2148-6-84.

14. Goris J, Konstantinidis KT, Klappenbach JA, Coenye T, Vandamme P, Tiedje JM. DNA-DNA hybridization values and their relationship to whole-genome sequence similarities. Int J Syst Evol Microbiol. 2007;57(Pt 1):81-91. doi:10. 1099/ijs.0.64483-0.

15. Barton MD, Petronio M, Giarrizzo JG, Bowling BV, Barton HA. The genome of Pseudomonas fluorescens strain R124 demonstrates phenotypic adaptation to the mineral environment. J Bacteriol. 2013; 195(21):4793-803. doi:10.1128/JB.00825-13.

16. Kim M, Oh HS, Park SC, Chun J. Towards a taxonomic coherence between average nucleotide identity and $16 \mathrm{~S}$ rRNA gene sequence similarity for species demarcation of prokaryotes. Int J Syst Evol Microbiol. 2014;64(Pt 2): 346-51. doi:10.1099/ijs.0.059774-0.

17. Altschul SF, Gish W, Miller W, Myers EW, Lipman DJ. Basic local alignment search tool. J Mol Biol. 1990;215(3):403-10. doi:10.1016/S00222836(05)80360-2.

18. Hohnadel D, Meyer JM. Specificity of pyoverdine-mediated iron uptake among fluorescent Pseudomonas strains. J Bacteriol. 1988;170(10):4865-73.

19. Cornelis $P$, Matthijs $S$, Van Oeffelen L. Iron uptake regulation in Pseudomonas aeruginosa. Biometals. 2009;22(1):15-22. doi:10.1007/s10534008-9193-0. 
20. Wandersman C, Delepelaire P. Bacterial iron sources: from siderophores to hemophores. Annu Rev Microbiol. 2004;58:611-47. doi:10.1146/annurev. micro.58.030603.123811.

21. Cha JS, Cooksey DA. Copper resistance in Pseudomonas syringae mediated by periplasmic and outer membrane proteins. Proc Natl Acad Sci U S A. 1991;88(20):8915-9.

22. Nies DH. The cobalt, zinc, and cadmium efflux system CzcABC from Alcaligenes eutrophus functions as a cation-proton antiporter in Escherichia coli. J Bacteriol. 1995;177(10):2707-12.

23. Nies DH. Efflux-mediated heavy metal resistance in prokaryotes. FEMS Microbiol Rev. 2003;27(2-3):313-39.

24. Caille O, Rossier C, Perron K. A copper-activated two-component system interacts with zinc and imipenem resistance in Pseudomonas aeruginosa. J Bacteriol. 2007;189(13):4561-8. doi:10.1128/JB.00095-07.

25. Delmar JA, Su CC, Yu EW. Bacterial multidrug efflux transporters. Annu Rev Biophys. 2014;43:93-117. doi:10.1146/annurev-biophys-051013-022855.

26. Hassan MT, van der Lelie D, Springael D, Romling U, Ahmed N, Mergeay M. Identification of a gene cluster, czr, involved in cadmium and zinc resistance in Pseudomonas aeruginosa. Gene. 1999;238(2):417-25.

27. Goldberg M, Pribyl T, Juhnke S, Nies DH. Energetics and topology of CzcA, a cation/proton antiporter of the resistance-nodulation-cell division protein family. J Biol Chem. 1999;274(37):26065-70.

28. Liu L, Chen H, Brecher MB, Li Z, Wei B, Nandi B, et al. Pfit is a structurally novel Crohn's disease-associated superantigen. PLoS Pathog. 2013;9(12): e1003837. doi:10.1371/journal.ppat.1003837.

29. Wei B, Huang T, Dalwadi H, Sutton CL, Bruckner D, Braun J. Pseudomonas fluorescens encodes the Crohn's disease-associated 12 sequence and T-cell superantigen. Infect Immun. 2002;70(12):6567-75.

30. Peabody CR, Chung YJ, Yen MR, Vidal-Ingigliardi D, Pugsley AP, Saier Jr MH. Type II protein secretion and its relationship to bacterial type IV pili and archaeal flagella. Microbiology. 2003;149(Pt 11):3051-72.

31. Sandkvist M. Type II, secretion and pathogenesis. Infect Immun. 2001;69(6): 3523-35. doi:10.1128/IAl.69.6.3523-3535.2001.

32. Cianciotto NP. Type II, secretion: a protein secretion system for all seasons. Trends Microbiol. 2005;13(12):581-8. doi:10.1016/j.tim.2005.09.005.

33. Filloux A. The underlying mechanisms of type II protein secretion. Biochim Biophys Acta. 2004;1694(1-3):163-79. doi:10.1016/j.bbamcr.2004.05.003.

34. Ball G, Durand E, Lazdunski A, Filloux A. A novel type II secretion system in Pseudomonas aeruginosa. Mol Microbiol. 2002;43(2):475-85.

35. De Vrind J, De Groot A, Brouwers GJ, Tommassen J, De Vrind-De Jong E Identification of a novel Gsp-related pathway required for secretion of the manganese-oxidizing factor of Pseudomonas putida strain GB-1. Mol Microbiol. 2003:47(4):993-1006.

36. da Silva AC, Ferro JA, Reinach FC, Farah CS, Furlan LR, Quaggio RB, et al. Comparison of the genomes of two Xanthomonas pathogens with differing host specificities. Nature. 2002;417(6887):459-63. doi:10.1038/417459a.

37. Salmond GP, Reeves PJ. Membrane traffic wardens and protein secretion in gram-negative bacteria. Trends Biochem Sci. 1993;18(1):7-12.

38. Lindgren PB, Peet RC, Panopoulos NJ. Gene cluster of Pseudomonas syringae pv. "phaseolicola" controls pathogenicity of bean plants and hypersensitivity of nonhost plants. J Bacteriol. 1986;168(2):512-22.

39. Marchi M, Boutin M, Gazengel K, Rispe C, Gauthier JP, Guillerm-Erckelboudt $A Y$, et al. Genomic analysis of the biocontrol strain Pseudomonas fluorescens Pf29Arp with evidence of T3SS and T6SS gene expression on plant roots. Environ Microbiol Rep. 2013;5(3):393-403. doi:10.1111/17582229.12048.

40. Preston GM, Bertrand N, Rainey PB. Type III secretion in plant growth-promoting Pseudomonas fluorescens SBW25. Mol Microbiol. 2001;41(5):999-1014.

41. Rezzonico F, Binder C, Defago G, Moenne-Loccoz Y. The type III secretion system of biocontrol Pseudomonas fluorescens KD targets the phytopathogenic Chromista Pythium ultimum and promotes cucumber protection. Mol Plant Microbe Interact. 2005;18(9):991-1001. doi:10.1094/ MPMI-18-0991.

42. Redondo-Nieto M, Barret M, Morrisey JP, Germaine K, Martinez-Granero F,

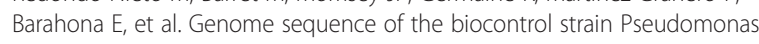
fluorescens F113. J Bacteriol. 2012;194(5):1273-4. doi:10.1128/JB.06601-11.

43. Ma Q, Zhai Y, Schneider JC, Ramseier TM, Saier Jr MH. Protein secretion systems of Pseudomonas aeruginosa and P fluorescens. Biochim Biophys Acta. 2003;1611(1-2):223-33.

44. Rainey PB. Adaptation of Pseudomonas fluorescens to the plant rhizosphere. Environ Microbiol. 1999;1(3):243-57.
45. Mattick JS. Type IV, pili and twitching motility. Annu Rev Microbiol. 2002;56: 289-314. doi:10.1146/annurev.micro.56.012302.160938.

46. Craig L, Li J. Type IV pili: paradoxes in form and function. Curr Opin Struct Biol. 2008;18(2):267-77. doi:10.1016/j.sbi.2007.12.009.

47. Planet PJ, Kachlany SC, Fine DH, DeSalle R, Figurski DH. The Widespread Colonization Island of Actinobacillus actinomycetemcomitans. Nat Genet. 2003;34(2):193-8. doi:10.1038/ng1154.

48. Tomich M, Planet PJ, Figurski DH. The tad locus: postcards from the widespread colonization island. Nat Rev Microbiol. 2007;5(5):363-75. doi:10.1038/nrmicro1636

49. Wagner VE, Bushnell D, Passador L, Brooks Al, Iglewski BH. Microarray analysis of Pseudomonas aeruginosa quorum-sensing regulons: effects of growth phase and environment. J Bacteriol. 2003;185(7):2080-95.

50. Schuster M, Lostroh CP, Ogi T, Greenberg EP. Identification, timing, and signal specificity of Pseudomonas aeruginosa quorum-controlled genes: a transcriptome analysis. J Bacteriol. 2003;185(7):2066-79.

51. Gerlach RG, Hensel M. Protein secretion systems and adhesins: the molecular armory of Gram-negative pathogens. Int J Med Microbiol. 2007; 297(6):401-15. doi:10.1016/j.jjmm.2007.03.017.

52. Boyer F, Fichant G, Berthod J, Vandenbrouck Y, Attree I. Dissecting the bacterial type $\mathrm{VI}$ secretion system by a genome wide in silico analysis: what can be learned from available microbial genomic resources? BMC Genomics. 2009;10:104. doi:10.1186/1471-2164-10-104.

53. Barret M, Egan F, Fargier E, Morrissey JP, O'Gara F. Genomic analysis of the type VI secretion systems in Pseudomonas spp.: novel clusters and putative effectors uncovered. Microbiology. 2011;157(Pt 6):1726-39. doi: 10.1099/mic.0.048645-0.

54. Suarez G, Sierra JC, Sha J, Wang S, Erova TE, Fadl AA, et al. Molecular characterization of a functional type $\mathrm{VI}$ secretion system from a clinical isolate of Aeromonas hydrophila. Microb Pathog. 2008;44(4):344-61. doi:10.1016/j.micpath.2007.10.005.

55. Kitaoka M, Miyata ST, Brooks TM, Unterweger D, Pukatzki S. VasH is a transcriptional regulator of the type $\mathrm{VI}$ secretion system functional in endemic and pandemic Vibrio cholerae. J Bacteriol. 2011;193(23):6471-82. doi:10.1128/JB.05414-11.

56. Bernard CS, Brunet YR, Gavioli M, Lloubes R, Cascales E. Regulation of type $\mathrm{VI}$ secretion gene clusters by sigma54 and cognate enhancer binding proteins. J Bacteriol. 2011;193(9):2158-67. doi:10.1128/JB.00029-11.

57. Doucleff M, Pelton JG, Lee PS, Nixon BT, Wemmer DE. Structural basis of DNA recognition by the alternative sigma-factor, sigma54. J Mol Biol. 2007; 369(4):1070-8. doi:10.1016/j.jmb.2007.04.019.

58. Potvin E, Sanschagrin F, Levesque RC. Sigma factors in Pseudomonas aeruginosa. FEMS Microbiol Rev. 2008;32(1):38-55. doi:10.1111/j.1574-6976. 2007.00092.x.

59. Leung KY, Siame BA, Snowball H, Mok YK. Type VI secretion regulation: crosstalk and intracellular communication. Curr Opin Microbiol. 2011;14(1): 9-15. doi:10.1016/j.mib.2010.09.017.

60. Shapiro RS, Cowen LE. Thermal control of microbial development and virulence: molecular mechanisms of microbial temperature sensing. MBio. 2012;3(5). doi:10.1128/mBio.00238-12.

61. Perron K, Caille O, Rossier C, Van Delden C, Dumas JL, Kohler T. CzcR-CzcS, a two-component system involved in heavy metal and carbapenem resistance in Pseudomonas aeruginosa. J Biol Chem. 2004;279(10):8761-8. doi:10.1074/jbc.M312080200.

62. Tamber S, Ochs MM, Hancock RE. Role of the novel OprD family of porins in nutrient uptake in Pseudomonas aeruginosa. J Bacteriol. 2006;188(1):45-54. doi: 10.1128/JB.188.1.45-54.2006

63. Blindauer CA, Harrison MD, Parkinson JA, Robinson AK, Cavet JS, Robinson NJ, et al. A metallothionein containing a zinc finger within a four-metal cluster protects a bacterium from zinc toxicity. Proc Natl Acad Sci U S A. 2001;98(17): 9593-8. doi:10.1073/pnas.171120098.

64. McArthur JV, Tuckfield RC. Spatial patterns in antibiotic resistance among stream bacteria: effects of industrial pollution. Appl Environ Microbiol. 2000; 66(9):3722-6.

65. Rasmussen LD, Sorensen SJ. The effect of longterm exposure to mercury on the bacterial community in marine sediment. Curr Microbiol. 1998;36(5):291-7.

66. Stepanauskas $\mathrm{R}$, Glenn $\mathrm{TC}$, Jagoe $\mathrm{CH}$, Tuckfield RC, Lindell AH, McArthur $\mathrm{JV}$. Elevated microbial tolerance to metals and antibiotics in metalcontaminated industrial environments. Environ Sci Technol. 2005;39(10):3671-8. 
67. Alonso A, Rojo F, Martinez JL. Environmental and clinical isolates of Pseudomonas aeruginosa show pathogenic and biodegradative properties irrespective of their origin. Environ Microbiol. 1999;1(5):421-30.

68. Wolfgang MC, Kulasekara BR, Liang X, Boyd D, Wu K, Yang Q, et al. Conservation of genome content and virulence determinants among clinical and environmental isolates of Pseudomonas aeruginosa. Proc Natl Acad Sci U S A. 2003;100(14):8484-9. doi:10.1073/pnas.0832438100.

69. Barbier M, Damron FH, Bielecki P, Suarez-Diez M, Puchalka J, Alberti S, et al. From the environment to the host: re-wiring of the transcriptome of Pseudomonas aeruginosa from 22 degrees C to 37 degrees C. PLoS One. 2014;9(2):e89941. doi:10.1371/journal.pone.0089941.

70. Shigemura K, Osawa K, Kato A, Tokimatsu I, Arakawa S, Shirakawa T, et al. Association of overexpression of efflux pump genes with antibiotic resistance in Pseudomonas aeruginosa strains clinically isolated from urinary tract infection patients. J Antibiot (Tokyo). 2015. doi:10.1038/ja.2015.34.

71. Ciofu O, Giwercman B, Pedersen SS, Hoiby N. Development of antibiotic resistance in Pseudomonas aeruginosa during two decades of antipseudomonal treatment at the Danish CF Center. Apmis. 1994;102(9):674-80.

72. Islam S, Oh H, Jalal S, Karpati F, Ciofu O, Hoiby N, et al. Chromosomal mechanisms of aminoglycoside resistance in Pseudomonas aeruginosa isolates from cystic fibrosis patients. Clin Microbiol Infect. 2009;15(1):60-6. doi:10.1111/j.1469-0691.2008.02097.x.

73. Jalal S, Ciofu O, Hoiby N, Gotoh N, Wretlind B. Molecular mechanisms of fluoroquinolone resistance in Pseudomonas aeruginosa isolates from cystic fibrosis patients. Antimicrob Agents Chemother. 2000;44(3):710-2.

74. Breidenstein EB, de la Fuente-Nunez C, Hancock RE. Pseudomonas aeruginosa: all roads lead to resistance. Trends Microbiol. 2011;19(8):419-26. doi:10.1016/j.tim.2011.04.005.

75. Eden PA, Schmidt TM, Blakemore RP, Pace NR. Phylogenetic analysis of Aquaspirillum magnetotacticum using polymerase chain reaction-amplified 16S rRNA-specific DNA. Int J Syst Bacteriol. 1991;41(2):324-5.

76. Rissman Al, Mau B, Biehl BS, Darling AE, Glasner JD, Perna NT. Reordering contigs of draft genomes using the Mauve aligner. Bioinformatics. 2009; 25(16):2071-3. doi:10.1093/bioinformatics/btp356.

77. Aziz RK, Bartels D, Best AA, DeJongh M, Disz T, Edwards RA, et al. The RAST Server: rapid annotations using subsystems technology. BMC Genomics. 2008;9:75. doi:10.1186/1471-2164-9-75.

78. Overbeek R, Olson R, Pusch GD, Olsen GJ, Davis JJ, Disz T, et al. The SEED and the Rapid Annotation of microbial genomes using Subsystems Technology (RAST). Nucleic Acids Res. 2014;42(Database issue):D206-14. doi:10.1093/nar/gkt1226.

79. Pearson WR. BLAST and FASTA similarity searching for multiple sequence alignment. Methods Mol Biol. 2014;1079:75-101. doi:10.1007/978-1-62703646-7_5.

80. Katoh K, Misawa K, Kuma K, Miyata T. MAFFT: a novel method for rapid multiple sequence alignment based on fast Fourier transform. Nucleic Acids Res. 2002;30(14):3059-66.

81. Katoh K, Standley DM. MAFFT multiple sequence alignment software version 7: improvements in performance and usability. Mol Biol Evol. 2013; 30(4):772-80. doi:10.1093/molbev/mst010.

82. Kristensen DM, Kannan L, Coleman MK, Wolf YI, Sorokin A, Koonin EV, et al. A low-polynomial algorithm for assembling clusters of orthologous groups from intergenomic symmetric best matches. Bioinformatics. 2010;26(12): 1481-7. doi:10.1093/bioinformatics/btq229.

83. Contreras-Moreira B, Vinuesa P. GET_HOMOLOGUES, a versatile software package for scalable and robust microbial pangenome analysis. Appl Environ Microbiol. 2013;79(24):7696-701. doi:10.1128/AEM.02411-13.

84. Tatusov RL, Koonin EV, Lipman DJ. A genomic perspective on protein families. Science. 1997;278(5338):631-7.

85. Tatusov RL, Fedorova ND, Jackson JD, Jacobs AR, Kiryutin B, Koonin EV, et al. The COG database: an updated version includes eukaryotes. BMC Bioinformatics. 2003:4:41. doi:10.1186/1471-2105-4-41.

86. Gao F, Zhang CT. GC-Profile: a web-based tool for visualizing and analyzing the variation of GC content in genomic sequences. Nucleic Acids Res. 2006; 34(Web Server issue):W686-91. doi:10.1093/nar/gkl040.

87. Edgar RC. MUSCLE: multiple sequence alignment with high accuracy and high throughput. Nucleic Acids Res. 2004;32(5):1792-7. doi:10.1093/nar/gkh340

88. Darling AC, Mau B, Blattner FR, Perna NT. Mauve: multiple alignment of conserved genomic sequence with rearrangements. Genome Res. 2004; 14(7):1394-403. doi:10.1101/gr.2289704.

\section{Submit your next manuscript to BioMed Central and we will help you at every step:}

- We accept pre-submission inquiries

- Our selector tool helps you to find the most relevant journal

- We provide round the clock customer support

- Convenient online submission

- Thorough peer review

- Inclusion in PubMed and all major indexing services

- Maximum visibility for your research

Submit your manuscript at www.biomedcentral.com/submit 